\title{
Brazilian Journal of Chemical

\section{CFD MODELING OF TWO IMMISCIBLE FLUIDS MIXING IN A COMMERCIAL SCALE STATIC MIXER}

\author{
V. Abdolkarimi* and H. Ganji \\ Process \& Equipment Technology Development Division, Research Institute of Petroleum Industry, \\ (RIPI), Tehran, 1485733111, Iran. \\ Phone: (98 21) 482524 97, Fax: (98 21) 447397 13, \\ *E-mail: vabdolkarimi@gmail.com, Website: www.ripi.ir \\ E-mail: Ganjih@ripi.ir
}

(Submitted: July 23, 2013 ; Revised: November 26, 2013 ; Accepted: December 24, 2013)

\begin{abstract}
A Computational Fluid Dynamics model based on the Eulerian formulation for multiphase flow was developed to model the mixing hydrodynamics of two immiscible fluids in a commercial scale static mixer. The two immiscible liquids were condensate and caustic solutions and were considered as two phases that are interpenetrating each other. The aim of this study was to develop a comprehensive Computational Fluid Dynamics model for predicting the impact of hydrodynamic parameters such as length, diameter and the arrangement of the corrugated plates of a static mixer on the degree of mixing and the pressure drop of the mixture. The model has been evaluated by comparing predictions of the degree of mixing and the mixture pressure drop with the same data available for the static mixer of the desulfurization plant of the Kharg petrochemical company. It has been shown that the predictions of the developed model are well adapted to the experimental data.

Keywords: CFD; Eulerian model; Static mixer; Hydrodynamics.
\end{abstract}

\section{INTRODUCTION}

Demercaptanization of condensate products (DMC) is widely used in the petroleum industry to remove $\mathrm{COS}, \mathrm{H}_{2} \mathrm{~S}, \mathrm{CS}_{2}$ and mercaptans existing in condensate products. There are different kinds of demercaptanizaton technologies with respect to the various amounts and kinds of mercaptans which are included in condensate products. The most complete demercaptanizaton technology is DMC-3. In this process, $\mathrm{COS}, \mathrm{H}_{2} \mathrm{~S}, \mathrm{CS}_{2}$ and light mercaptans are removed from condensate using 10 weight percent caustic solution. Caustic solution cannot extract heavy mercaptans. In this case, they are oxidized to disulphide in the presence of enriched oxygen air ( 60 percent of oxygen by weight), caustic solution and IVKAZ catalyst. In addition, for the separation of light mercaptans from caustic solution, the solution is oxidized over the IVKAZ catalyst. After oxidation, light mercaptans are converted to disulphide and separated from the caustic solution. The caustic which is recovered in the oxidation unit is sent to the extraction unit for extracting light mercaptans.

The yield of the DMC process depends on the complete mixing of caustic solution and gas condensate, which are immiscible fluids. There are two procedures for mixing fluids: batch mixing and continuous mixing. In terms of batch mixing, a predetermined volume of fluids is mixed in a vessel. In this process, there is no need for a sophisticated control system, but it is inappropriate for mixing large amounts of fluids because large vessels are required.

*To whom correspondence should be addressed 
On the other hand, continuous mixing is used for mixing large amount of fluids and usually requires a complicated control system; hence it is more expensive than a batch procedure. The continuous method is especially used when direct delivering of blending products to consumers is required. In the continuous mixing method, a static mixer is used as the in line blending unit, which promotes the yield of the mixing process. The special geometry of a static mixer increases the mixing efficiency of fluids.

The main principles of static mixers are well described in the open literature (Grace, 1971; Cybulski and Werner, 1986; Mutsakis et al., 1986; Myers et al., 1997; Thakur et al., 2003). They may be used in order to carry out every mixing operation such as mixing of miscible fluids, heat transfer and thermal homogenization, or liquid-liquid dispersion, as well as gas-liquid dispersion. Static mixers offer advantages such as no moving parts, small space requirements, little or no maintenance requirements, many construction materials, narrow residence time distributions, enhanced heat transfer, and low power requirements. In fact, the only energy cost, represented by motionless mixers, comes from the external pumping power needed to propel materials through the mixer. That is why their use for continuous processes is an attractive alternative to classical agitation devices, since similar and sometimes better performances can be achieved at a lower cost (Theron and Sauze, 2011).

If static mixers find many industrial applications for mixing of miscible liquids, there are few examples of emulsification with static mixers. The most investigated mixer for liquid-liquid dispersion in turbulent flow in the literature is the classical Kenics helical mixer (Middleman, 1974; Chen and Libby, 1978; Haas, 1987; Berkman and Calabrese, 1988; Yamamoto, 2007). Emulsification, using the Sulzer SMX mixer, has been studied not only in laminar flow (Legrand et al., 2001; Das et al., 2005; Liu et al., 2005; Rama Rao et al., 2007; Fradette et al., 2007; Gingras et al., 2007) but also in turbulent regime (Streiff et al., 1997). Results for liquid-liquid dispersion are also reported in the literature using the SMV mixer (Streiff, 1977).

With respect to the important role of the geometrical parameters of a static mixer, in this study we use CFD modeling as a powerful tool for evaluating the influence of geometrical parameters (such as length, diameter and pressure drop that are caused by special arrangement of static mixer planes) on mixing efficiency and the pressure drop of a commercial scale static mixer which is employed in the DMC unit of the Kharg petrochemical company.

\section{INDUSTRIAL STATIC MIXER}

For the mixing of low viscosity fluids, a special kind of static mixer such as the GV static mixer, made by the Stamix Company, is used. The GV static mixer is considered to be a high intensity design that creates a homogeneous mix in just a few pipe diameters. It is made of corrugated plates that are stacked on top of each other in an alternating-crossing fashion to form open intersecting channels that are at a $45^{\circ}$ angle relative to the pipe axis. Adjacent mixing elements are oriented $90^{\circ}$ relative to each other to create 3-dimensional mixing (Figure 1). The "GV" static mixer is utilized primarily in turbulent flow applications and creates a very high degree of mixing in a short length. Typical applications include the mixing of low viscosity liquids, mixing of gases, gas-liquid contacting and immiscible liquid dispersion (www.stamixco.com).

The GV static mixer continuously divides and recombines the process streams to be mixed along the entire length of the mixing unit (Figure 2). In gas-liquid contacting and immiscible liquid dispersion applications, the high shear field, created at each of the crossing points of adjacent corrugated plates, assures that intense mixing and contacting occurs over the entire volume of the mixer diameter and length. This generates small droplets/bubbles of a consistent size that are evenly distributed throughout the entire pipe diameter, resulting in high mass transfer rates.

The degree of mixing and the pressure drop per unit length of a mixer can be dialed in by varying the mixing element geometric parameters. This is accomplished by varying the number of mixing layers (corrugated plates), corrugated plate angle relative to the pipe axis, mixing element $\mathrm{L} / \mathrm{D}$ and the use of spacers between mixing elements to enhance homogeneity with little pressure drop.

The standard GV mixing element consists of five corrugated plates. In applications where high degrees of mixing, short length and high shear are critical parameters, the overall mixer length can be shortened by augmenting the number of mixing layers (corrugated plates, Figure 3 ).

The standard GV mixing element has a corrugated layer angle of $45^{\circ}$ relative to the pipe axis. In applications where low pressure drop is required, the angle is decreased to $30^{\circ}$, which dramatically lowers pressure drop.

The GV mixing element produces strong turbulent eddies downstream of each mixing element. In applications where pressure drop is of concern, but the length of mixing unit is not an issue, the installation of spacers between mixing elements will dramatically improve mixing for the same pressure drop (Figure 4). 

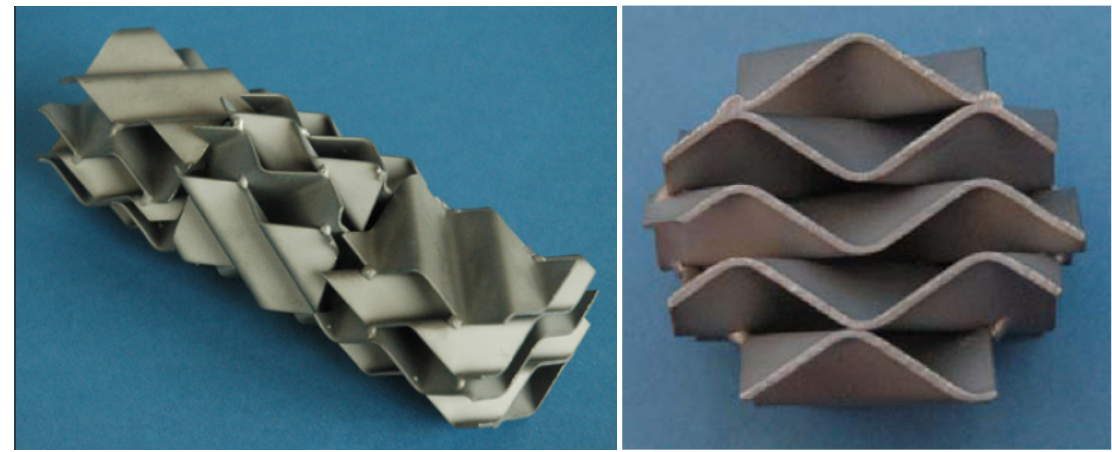

Figure 1: GV static mixer with three mixing elements. Each mixing element has 5 corrugated plate mixing layers stacked at alternating $45^{\circ}$ angles relative to the pipe axis.

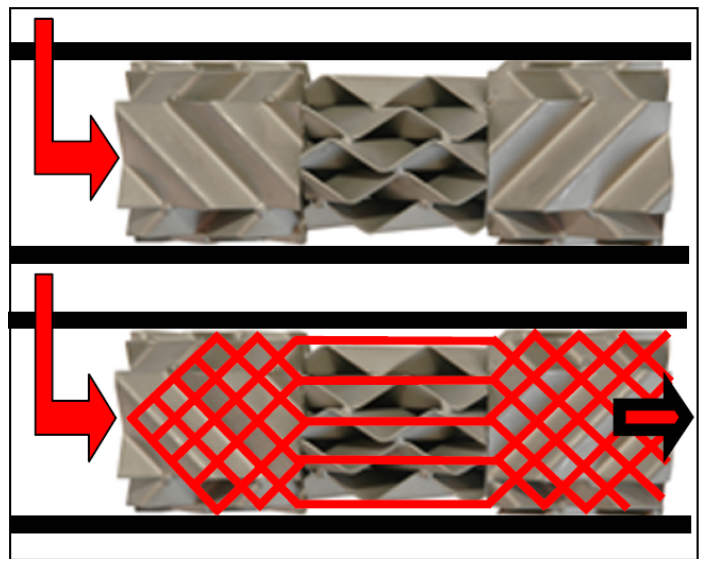

Figure 2: Flow pattern through three GV mixing elements of 5 layer construction. Note that adjacent mixing elements are oriented $90^{\circ}$ relative to each other.

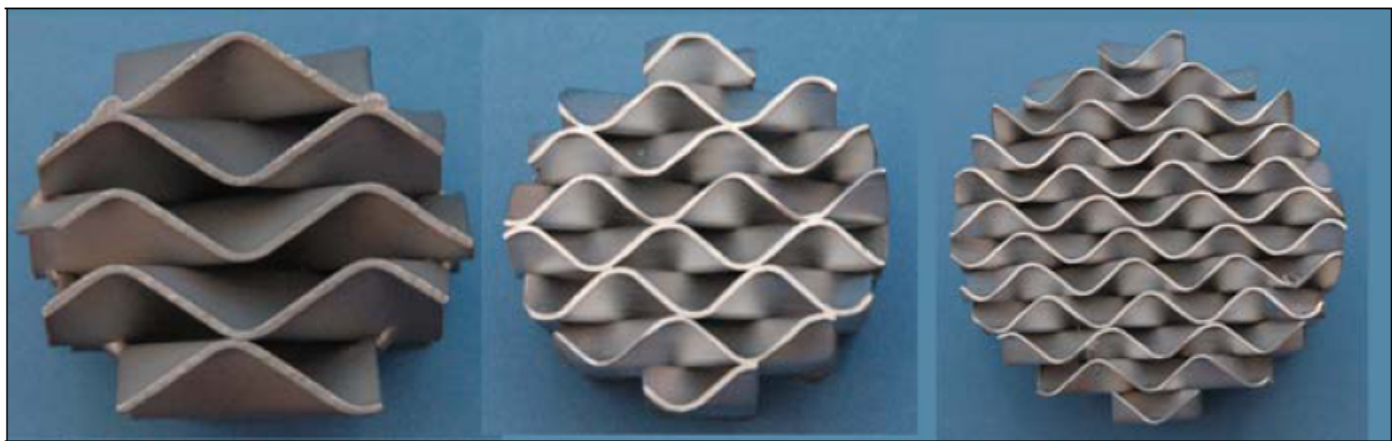

Figure 3: Number of mixing layers (corrugated plates) in a specific pipe size.

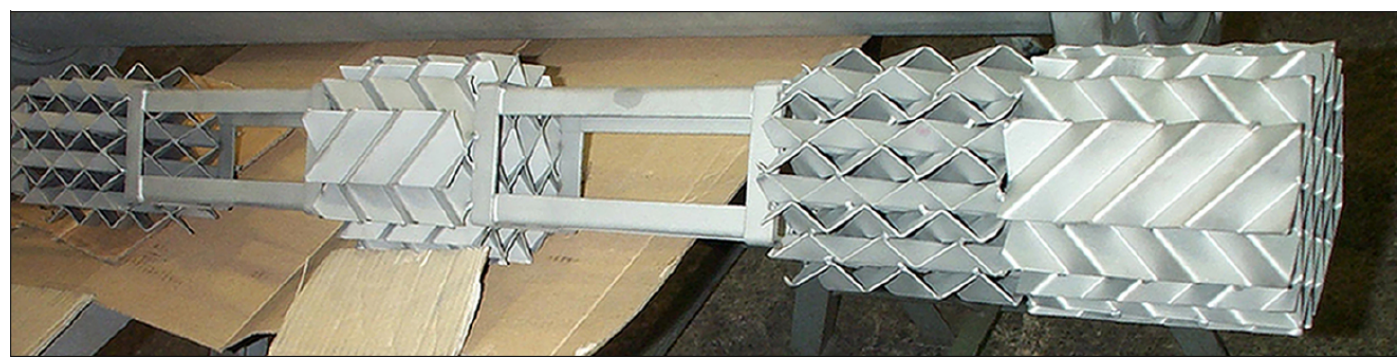

Figure 4: The incorporation of spacers between GV mixing elements improves the degree of mixing achieved by taking advantage of the strong turbulent eddies created at the outlet of each mixing element. 
The commercial scale static mixer of the Kharg petrochemical company has five corrugated plates in each mixing element that are aligned at the angle of $45^{\circ}$ relative to the pipe axis. For each mixing element, the ratio of $\mathrm{L} / \mathrm{D}$ is equal to unity. There are 6 mixing elements with spacers between them. The diameter and length of the static mixer are 10 inches and 3 meters, respectively. The geometry of the commercial static mixer is depicted in Figure 5 and the specifications are given in Table 1.
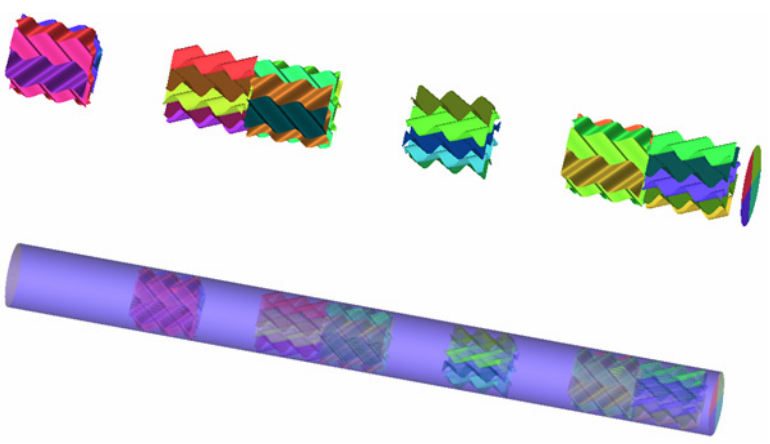

Figure 5: Geometry of the commercial static mixer.

Table 1: Specifications of commercial static mixer.

\begin{tabular}{|l|c|}
\hline Length of static mixer $(\mathrm{m})$ & 3 \\
Diameter of static mixer $(\mathrm{m})$ & 0.254 \\
Number of mixing elements & 6 \\
Length of mixing element $(\mathrm{m})$ & 0.254 \\
Angle of mixing element corrugated plates (D) & $45^{\circ}$ \\
Number of spacers & 3 \\
Length of spacer (m) & 0.254 \\
\hline
\end{tabular}

\section{COMPUTATIONAL MODEL}

CFD modeling involves three main steps: (1) Creating the model geometry and grid. (2) Defining the appropriate physical models and (3) Defining the boundary and operating conditions. The governing conservation equations of mass, momentum and physical models involved in the process are discretized over control volumes and solved by a finite volume method via the Fluent 6.3.3 commercial CFD toolbox. The whole volume of the static mixer is divided into 14 million tetrahedral control volumes. The mesh which is generated near the wall surfaces was refined to achieve the adequate $\mathrm{y}^{+}$value $\left(\mathrm{y}^{+}<300\right)$. The grid that is created on the surface of the corrugated plates is shown in Figure 6.

To solve the conservation equations, the fluid conditions at the inlet and outlet boundaries should be determined. Therefore, fluid conditions for condensate and caustic solution are given in Table 2.

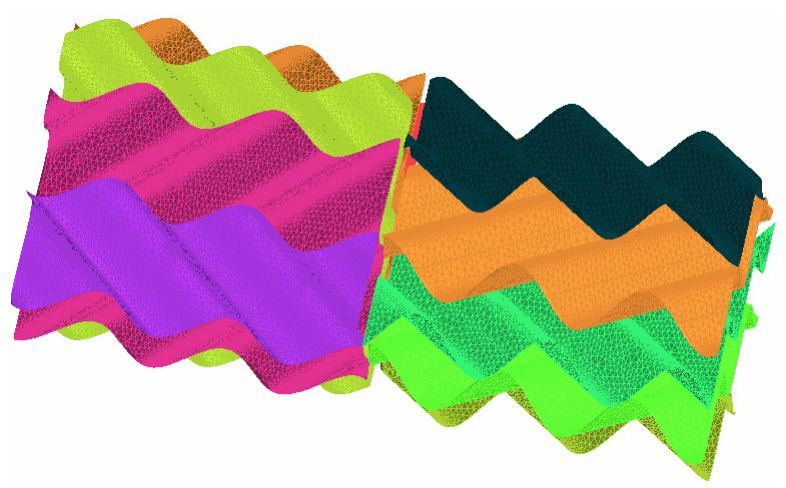

Figure 6: Triangular grids on the surface of the corrugated plates.

Table 2: Fluid conditions.

\begin{tabular}{|c|c|c|c|}
\hline \multirow{2}{*}{ Run Case } & \multicolumn{3}{|c|}{ Winter Case } \\
\cline { 2 - 4 } Fluid name & $\begin{array}{c}\text { Stabilized } \\
\text { condensate }\end{array}$ & $\begin{array}{c}\text { Caustic } \\
\text { solution } \\
(\mathbf{1 0 \%})\end{array}$ & $\begin{array}{c}\text { Condensate } \\
\text { + caustic }\end{array}$ \\
\hline $\begin{array}{c}\text { Fluid quantity total } \\
\text { (kg/h) }\end{array}$ & 209393.6 & 15098.2 & 224491.8 \\
\hline $\begin{array}{c}\text { Liquid } \\
\text { (kg/h) }\end{array}$ & 209393.6 & 15098.2 & 224491.8 \\
\hline \multirow{2}{*}{$\begin{array}{c}\text { Liquid } \\
\text { Density } \\
\left(\mathbf{k g} / \mathbf{m}^{\mathbf{3}}\right)\end{array}$} & 714.7 & 1103.9 & 728.9 \\
\hline $\begin{array}{c}\text { Viscosity } \\
(\mathbf{k g} /(\mathbf{m . s}) \mathbf{s}\end{array}$ & $4.44 \mathrm{E}-4$ & $9.5 \mathrm{E}-4$ & $5.5 \mathrm{E}-4$ \\
\hline $\begin{array}{c}\text { Surface } \\
\text { Tension } \\
\mathbf{N} / \mathbf{m}\end{array}$ & $1.83 \mathrm{E}-4$ & $7.5 \mathrm{E}-4$ & $2.15 \mathrm{E}-4$ \\
\hline
\end{tabular}

The two-phase flow equations are solved in the Eulerian framework that considers two fluids as a continuous phase that are penetrating each other. The contribution of each phase in the continuity and momentum equations is attended by the volume fraction of each phase. This problem can be solved in steady state mode, but it is likely to lead to convergence problems; therefore, the unsteady state formulation is used. The time step size is selected as 0.001 seconds and the initial conditions are as follows:

Volume fraction of caustic solution $=0$, Velocity of condensate $=0.5 \mathrm{~m} / \mathrm{s}$, Turbulent intensity of condensate phase $=0.01$. After 30 seconds the numerical solution approaches steady conditions.

The continuity equation for each phase is:

$\frac{\partial\left(\alpha_{q} \rho_{q}\right)}{\partial t}+\nabla \cdot\left(\alpha_{q} \rho_{q} \overrightarrow{U_{q}}\right)=0$

where $\overrightarrow{U_{q}}$ is the velocity and $\alpha_{q}$ is the volume fraction of each phase.

The momentum balance equation for each phase is: 


$$
\begin{aligned}
& \frac{\partial}{\partial t}\left(\alpha_{q} \rho_{q} \vec{U}_{q}\right)+\nabla\left(\alpha_{q} \rho_{q} \vec{U}_{q} \vec{U}_{q}\right)= \\
& -\alpha_{q} \nabla P+\nabla \overline{\tau_{q}}+\sum_{p=1}^{n} \vec{R}_{p q}+\alpha_{q} \rho_{q} g
\end{aligned}
$$

where $R_{P q}$ is the fluid-fluid drag force. The subscripts ' $\mathrm{p}$ ' and ' $\mathrm{q}$ ' refer to the discrete phase of caustic and continuous phase of condensate, respectively.

$$
F_{d r a g, P q}=\overrightarrow{R_{P q}}=\beta_{P q}\left(\vec{U}_{P}-\vec{U}_{q}\right)
$$

where $\beta_{P q}$ is the fluid-fluid drag coefficient.

$$
\beta_{P q}=\frac{\alpha_{q} \alpha_{p} \rho_{p} f}{\tau_{p}}
$$

where $f$, the drag function, is defined differently for the different exchange-coefficient models and the $\tau_{p}$ "particulate relaxation time" is defined as:

$$
\tau_{p}=\frac{\rho_{p} d_{p}^{2}}{18 \mu_{q}}
$$

where $d_{p}$ is the diameter of the droplets of phase $p$.

For the model of Schiller and Naumann, (1935):

$f=\frac{C_{D} \mathrm{Re}}{24}$

$C_{D}= \begin{cases}24\left(1+0.15 \mathrm{Re}^{0.687}\right) / \mathrm{Re} & \mathrm{Re} \leq 1000 \\ 0.44 & \mathrm{Re}>1000\end{cases}$

$R e$ is the relative Reynolds number. The relative Reynolds number for the primary phase $k$ and secondary phase $p$ is obtained from:

$\operatorname{Re}=\frac{\rho_{q}\left|\vec{U}_{p}-\vec{U}_{q}\right| d_{p}}{\mu_{q}}$

Due to the high strain rate of fluid between corrugated plates, the Realizable k-e model is applied for modeling the effect of turbulence on flow field velocities (Shih et al., 1995).

$$
\begin{aligned}
\frac{\partial}{\partial t}\left(\rho_{q} k_{q}\right)+\nabla \cdot\left(\rho_{q} k_{q} \overrightarrow{U_{q}}\right) & =\nabla\left[\left(\mu+\frac{\mu_{t, q}}{\sigma_{k}}\right) \nabla k_{q}\right] \\
& +G_{k, q}-\rho_{q} \varepsilon_{q}
\end{aligned}
$$

$$
\begin{aligned}
& \frac{\partial}{\partial t}\left(\rho_{q} \varepsilon_{q}\right)+\nabla \cdot\left(\rho_{q} \varepsilon_{q} \overrightarrow{U_{q}}\right) \\
& =\nabla\left[\left(\mu+\frac{\mu_{t, q}}{\sigma_{k}}\right) \nabla \varepsilon_{q}\right]+\varepsilon_{q}\left(-\rho_{q} C_{2} \frac{\varepsilon_{q}}{k_{q}+\sqrt{v_{q} \varepsilon_{q}}}\right)
\end{aligned}
$$

where $\sigma_{\varepsilon}, \sigma_{k}$ are turbulent Prandtl numbers and $\mu_{t, q}$ is the turbulent viscosity.

$k_{q}$ and $\varepsilon_{q}$ are turbulent kinetic energy and dissipation rate, respectively.

$$
\begin{aligned}
& \mu_{t}=\rho C_{\mu} \frac{k^{2}}{\varepsilon} \\
& C_{\mu}=\frac{1}{A_{0}+A_{S} \frac{k U^{*}}{\varepsilon}} \\
& U^{*}=\sqrt{S_{i j} S_{i j}} \\
& A_{0}=4.04, \mathrm{~A}_{\mathrm{S}}=\sqrt{6} \cos \phi \\
& \varphi=\frac{1}{3} \cos ^{-1}(\sqrt{6} W), W=\frac{S_{i j} S_{j k} S_{k i}}{\tilde{S}^{3}}, \\
& \tilde{S}=\sqrt{S_{i j} S_{i j}}, S_{i j}=\frac{1}{2}\left(\frac{\partial U_{j}}{\partial x_{i}}+\frac{\partial U_{i}}{\partial x_{j}}\right)
\end{aligned}
$$

\section{RESULTS AND DISCUSSION}

By using CFD modelling, we can estimate precisely the velocity and volume fraction distribution of the caustic solution as the secondary phase and gas condensate as the primary phase. According to Table 2, the volume fraction of caustic at inlet would be 0.045 if caustic solution and condensate were mixed completely. At the inlet boundary, two phases enter separately for evaluating the performance of a commercial static mixer for mixing of two fluids. The entering face of the static mixer is divided into two semi-circles and phases which enter the mixer through the semi-circles separately at specified mass flow rates (Table 2). The Eulerian formulation of multiphase flow is used to describe the motion of each phase.

In Figure 7, the velocity vectors of condensate at (a) inlet (b) the middle of mixer and (c) at the end of the static mixer are depicted. As can be seen, the intensive strain rate in flow streams, which is produced 
due to the existence of the corrugated plates, makes it essential to use a proper turbulent model that can evaluate the velocity field for both fluids correctly. Hence, the realizable k-e model was selected to predict turbulent flow field velocities. The purpose of using a static mixer is perfect mixing of fluids, which is obtained by dividing flow streams, radial mixing and vortex creation in a static mixer. The flow patterns of condensate can be recognized from the velocity vectors.
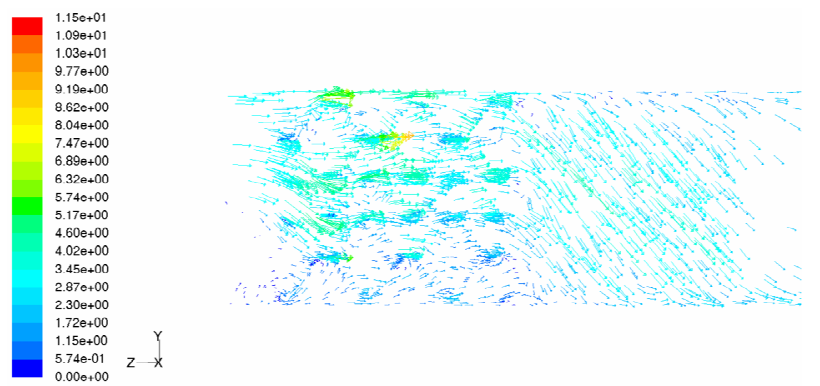

(a)

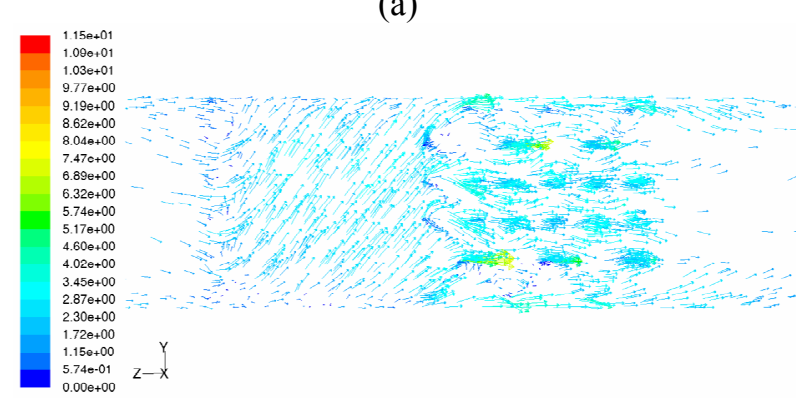

(b)

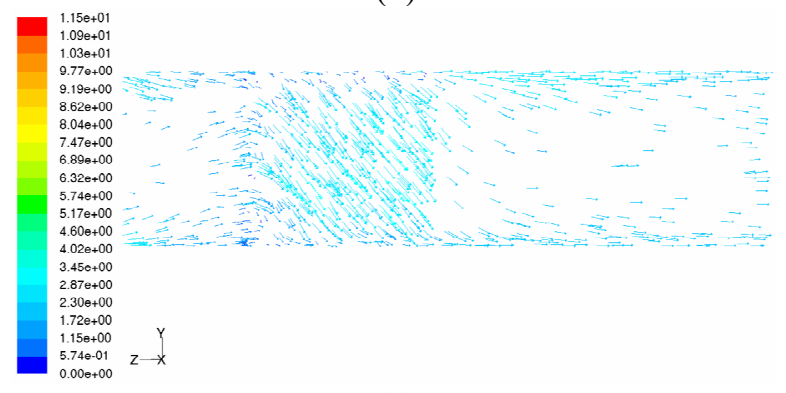

(c)

Figure 7: The velocity vectors of condensate $(\mathrm{m} / \mathrm{s})$ at the (a) inlet, (b) middle, (c) outlet of the static mixer on a longitudinal section.

In Figure 8, the contours of condensate volume fraction at (a) the inlet (b) the middle of mixer and (c) the end of static mixer are shown. As is obvious, at the inlet of static mixer two fluids enter separately from two inlet boundaries and then, after crossing the corrugated plates, the direction of flow changes dramatically. This direction change leads to mixing of fluids, which is completed at the end of the mixer.
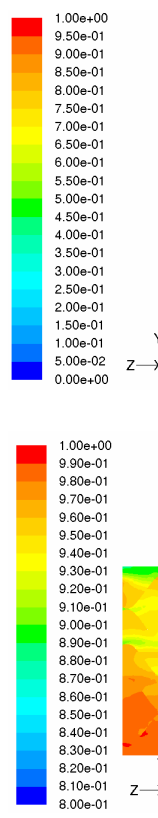

$1.00 e+00$
$9.90 \mathrm{e}-01$

$9.90 \mathrm{e}-01$
$9.80 \mathrm{e}-01$

$9.80 \mathrm{e}-01$
$9.70 \mathrm{e}-01$
$9.60 \mathrm{e}-01$

$9.50 \mathrm{e}-01$

$9.400-01$

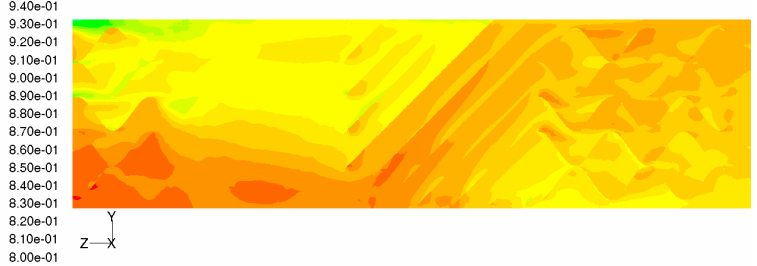

$8.00-01$

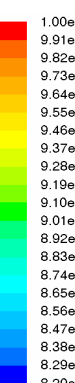

$1.00 e+00$
$9.91 \mathrm{e}-01$
$9.82 \mathrm{e}-01$
$9.73 \mathrm{e}-01$
$9.64 \mathrm{e}-01$
$9.55 \mathrm{e}-01$
$9.46 \mathrm{e}-01$
$9.37 \mathrm{e}-01$
$9.28 \mathrm{e}-01$
$9.190-01$
$9.10 \mathrm{e}-01$
$9.01 \mathrm{e}-01$
$8.92 \mathrm{e}-01$
$8.83 \mathrm{e}-01$
$8.74 \mathrm{e}-01$
$8.65 \mathrm{e}-01$
$8.56 \mathrm{e}-01$
$8.47 \mathrm{e}-01$
$8.38 \mathrm{e}-0.1$
$8.29 \mathrm{e}-01$
$820 \mathrm{e}-01$

(b)

(a)

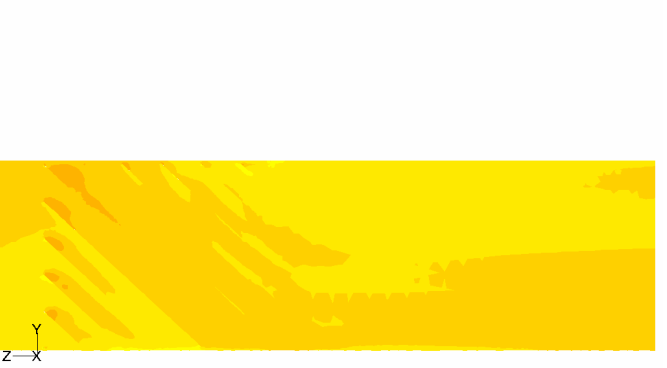

(c)

Figure 8: The volume fraction contours of condensate at the (a) inlet, (b) middle, and (c) outlet of the static mixer on a longitudinal section.

The degree of mixing can be shown by the volume fraction contours of caustic solution at each cross section through the length of the static mixer, which is depicted in Figure 9. According to this figure, it is clear that the most amount of mixing is carried out in the first half length of the static mixer and, in the next half, the degree of mixing decreases. The averaged values of caustic volume fraction over the cross-sectional planes are depicted in Figure 10. At the end length of $285 \mathrm{~cm}$ from the inlet of the static mixer, the contours show that the blending of two fluids has been completed and the volume fraction of caustic solution approaches its homogenized value of 0.045 . There are four sampling points along the static mixer length (at $Z=0.06 \mathrm{~m}, Z=0.86 \mathrm{~m}$, $Z=2.10 \mathrm{~m}, Z=3 \mathrm{~m}$ ), where the mixture sample and its density are obtained. The experimental measurements of mixture density are compared with similar 

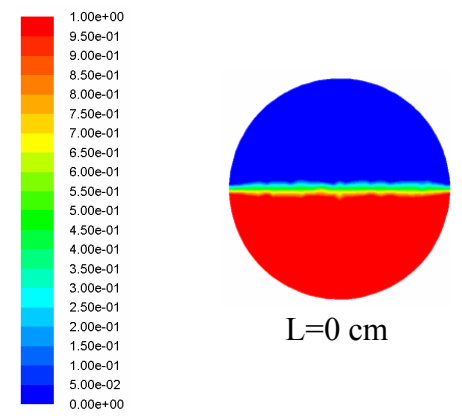

$\mathrm{L}=0 \mathrm{~cm}$

$3.00 \mathrm{e}-01$
$2.85 \mathrm{e}-01$
$2.70-01$

$2.70 \mathrm{e}-01$
$255-01$

$2.55 \mathrm{e}-01$
$240 \mathrm{e}-01$

$2.400-01$
$2.25 \mathrm{e}-01$
2.01

$2.25 \mathrm{e}-01$
$2.10 \mathrm{e}-01$

$1.958-01$
$1.80-01$

$1.80 \mathrm{e}-01$
$1.65 \mathrm{e}-0.1$

$1.50 \mathrm{e}-01$

$1.358-01$

$1.20 \mathrm{e}-01$

$1.055-01$
$9000-02$
$7.50-02$

$9.00 \mathrm{e}-02$
$7.50 \mathrm{e}-02$

$6.00 \mathrm{e}-02$

$6.00 \mathrm{e}-02$
$4.50 \mathrm{e}-02$

$3.00 \mathrm{e}-02$

$3.000-02$
$1.500-02$

$0.00 e+00$

$1.00 \mathrm{e}-01$
$9.50 \mathrm{e}-02$
9

$9.50 \mathrm{e}-02$
$9.00 \mathrm{\theta}-02$

$8.500 \cdot 02$

$8.00 \mathrm{e}-02$

$7.50 \mathrm{e}-02$

7.00e-02

$6.00 \mathrm{e}-02$

$5.50 \mathrm{e}-02$

$5.00 \mathrm{e}-02$

$4.50 \mathrm{e}-02$
$4.00 \mathrm{e}-02$

3.50e- 02

$3.00 \mathrm{e}-02$

$2.50 \mathrm{e}-02$

$2.00 \mathrm{e}-02$

$1.500-02$

$1.00 \mathrm{e}-02$

$0.00 \mathrm{e}+00$

$6.65 \mathrm{e}-02$

6.30e. 02

5.95e-02

$5.60 \mathrm{e}-02$

$5.25 \mathrm{e}-02$
$490 \mathrm{e}-02$

$45 \mathrm{e}-02$

$4.20 \mathrm{e}-02$

$3.85 \mathrm{e}-02$

3. $50 \mathrm{e}-02$

3.15e-02

$2.80 \mathrm{e}-02$

$2.45 \mathrm{e} .02$

..1.00

. $50 \mathrm{e}-03$

$0.00 \mathrm{e}+00$

$7.00 \mathrm{e}-02$
$6.65 \mathrm{e}-02$

6.30e-02

$5.95 \mathrm{e}-02$

$5.60 \mathrm{e}-02$

$5.25 \mathrm{e}-02$

$4.90 \mathrm{e}-02$

4.55e-02

$4.20 \mathrm{e}-02$

$3.85 \mathrm{e}-02$

$3.50 \mathrm{e}-02$

$2.150 \mathrm{e}-02$

$2.45 \mathrm{e}-02$

$1.75 \mathrm{e}-02$

$1.40 \mathrm{e}-02$

$0.00 e+00$

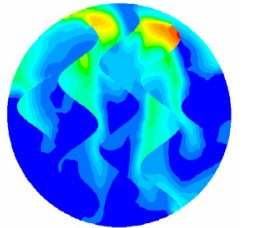

$\mathrm{L}=56 \mathrm{~cm}$

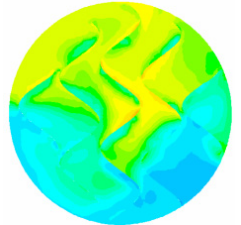

$\mathrm{L}=135 \mathrm{~cm}$

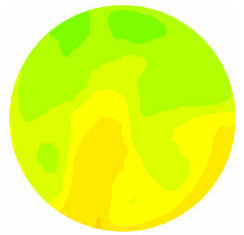

$\mathrm{L}=210 \mathrm{~cm}$

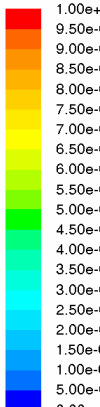

$50 \mathrm{e}-01$

$.00 \mathrm{e}-01$

$.50 \mathrm{e}-01$

$7.50 \mathrm{e}-01$

(7.50e-01

.

$5.50 \mathrm{e}-01$

$5.00 \mathrm{e}-01$

$4.50 \mathrm{e}-01$

. $50 \mathrm{e}-01$

$00 \mathrm{e}-0$

50e-01

$.000-01$
.500

$1.00 \mathrm{e}-01$
$5.00 \mathrm{e}-02$

$5.00 \mathrm{e}-02$
$0.00 \mathrm{e}+00$

1.50e-0

$1.43 \mathrm{e}-01$
$1.35 \mathrm{e}-01$

$1.35 \mathrm{e}-01$
$1.27 \mathrm{e}-01$

$1.20 \mathrm{e}-0$

$1.13 \mathrm{e}-0$
$1.05 \mathrm{e}-0$

$9.75 \mathrm{e}-02$

$9.00 \mathrm{e}-02$

$8.25 \mathrm{e}-02$

$7.50 \mathrm{e}-02$
$6.75 \mathrm{e}-02$

$6.00 \mathrm{e}-02$

$5.25 \mathrm{e}-02$

$4.50 \mathrm{e}-02$

$3.75 \mathrm{e}-02$

$2.25 \mathrm{e}-02$

$1.50 \mathrm{e}-02$

$7.50 \mathrm{e}-02$
$7.50 \mathrm{e}-03$
$0.00 \mathrm{e}+00$

\begin{tabular}{l}
$9.50 \mathrm{e}-02$ \\
$9.03 \mathrm{e}-02$ \\
$8.55 \mathrm{e}-02$ \\
$8.07 \mathrm{e}-02$ \\
\hline 7.02
\end{tabular}

$7.60 \mathrm{e}-02$

$7.12 \mathrm{e}-02$

$6.65 \mathrm{e}-02$

$6.17 \mathrm{e}-02$

$5.700-02$

$5.22 \mathrm{e}-02$

$4.75 \mathrm{e}-02$
$4.28 \mathrm{e}-02$

$3.80 \mathrm{e}-0$

$3.33 \mathrm{e}-02$

$2.85 \mathrm{e}-02$

2.37e-02

$1.90 \mathrm{e}-02$

$1.43 \mathrm{e}-02$

$9.50 \mathrm{e}-03$

$4.75 \mathrm{e}-03$

$.00 \mathrm{e}-02$

$6.65 \mathrm{e}-02$

6. $30 \mathrm{e}-02$

$5.95 \mathrm{e}-02$

$5.60 \mathrm{e}-02$

.

$4.55 e-02$

4. $20 \mathrm{e}-02$

3.85e-02

3. $50 \mathrm{e}-02$

$3.15 \mathrm{e}-02$
$2.80 \mathrm{e}-02$

$2.45 \mathrm{e}-02$

2. $10 \mathrm{e}-02$

$1.75 \mathrm{e}-02$
$1.40 \mathrm{e}-02$

$1.40 \mathrm{e}-02$

$7.00 \mathrm{e}-03$

$7.000 \mathrm{e}-03$
$0.00 \mathrm{e}+00$

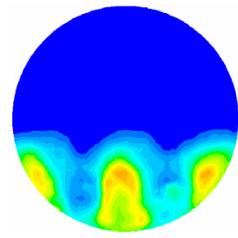

$\mathrm{L}=6 \mathrm{~cm}$

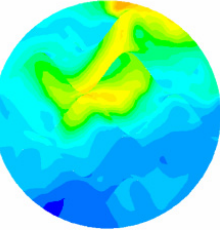

$\mathrm{L}=86 \mathrm{~cm}$

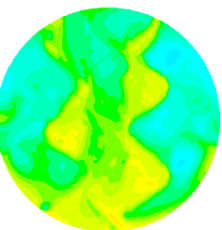

$\mathrm{L}=160 \mathrm{~cm}$

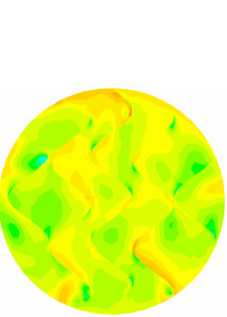

$\mathrm{L}=235 \mathrm{~cm}$

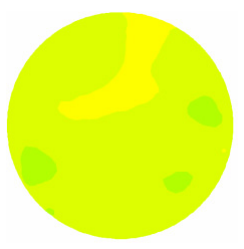

$\mathrm{L}=285 \mathrm{~cm}$

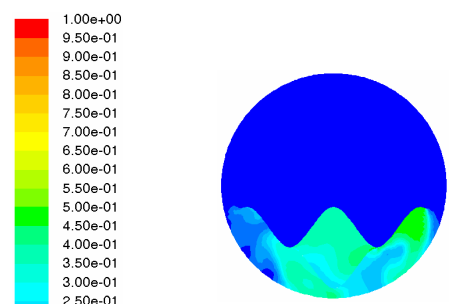

$\mathrm{L}=26 \mathrm{~cm}$

$2.00 \mathrm{e}-01$
$1.50 \mathrm{e}-01$

$1.00 \mathrm{e}-01$
$5.00 \mathrm{e}-02$

$1.00 \mathrm{e}-02$
$0.00 \mathrm{e}+00$

$1.00 \mathrm{e}-01$
$9.50 \mathrm{e}-02$
$9.00 \mathrm{e}-02$
$8.50 \mathrm{e}-02$
$8.00 \mathrm{e}$

$8.50 \mathrm{e}-02$
$8.00 \mathrm{e}-02$
$7.50 \mathrm{e}$

$7.50 \mathrm{e}-02$
$7.00 \mathrm{e}-02$

$6.50 \mathrm{e}-02$

6.00e-02

$5.50 \mathrm{e}-02$

$5.000-02$

4.500-02

$4.00 \mathrm{e}-02$

$3.50 \mathrm{e}-02$
$3.00 \mathrm{e}-02$

$3.00 \mathrm{e}-02$

$2.50 \mathrm{e}-02$
$2.00 \mathrm{e}-02$

$2.00 \mathrm{e}-02$
$1.50 \mathrm{e}-02$

$1.00 \mathrm{e}-02$

$5.00 \mathrm{e}-03$
$0.00 \mathrm{e}+00$

\begin{tabular}{|l}
\hline $.00 \mathrm{e}-02$ \\
$8.55 \mathrm{e}-02$ \\
$8.10 \mathrm{e}-02$ \\
$7.65 \mathrm{e}-02$ \\
7.02
\end{tabular}

$7.20 \mathrm{e}-02$
$6.75 \mathrm{e}-02$

$6.75 \mathrm{e}-02$
$6.30 \mathrm{e}-02$

$6.30 \mathrm{e}-02$
$5.85 \mathrm{e}-02$

$5.40 \mathrm{e}-02$

$4.95 \mathrm{e}-02$

$4.50 \mathrm{e}-02$
$4.05 \mathrm{e}-02$

$4.05 \mathrm{e}-02$
$3.60 \mathrm{e}-02$

$3.15 \mathrm{e}-02$

$3.15 \mathrm{e}-02$
$2.70 \mathrm{e}-02$

2.25e-02

$1.80 \mathrm{e}-02$

1.35e-02

$9.00 \mathrm{e}-03$

$0.00 e+00$

$7.00 \mathrm{e}-02$
$6.65 \mathrm{e}-02$
$6.30 \mathrm{e}-02$
5.02

$6.30 \mathrm{e}-02$
$5.95 \mathrm{e}-02$

$5.60 \mathrm{e}-02$

$5.25 \mathrm{e}-02$
$4.90 \mathrm{e}-02$

$4.55 \mathrm{e}-02$

$4.20 \mathrm{e}-02$

3.85e -02

$3.85 \mathrm{e}-02$
$3.50 \mathrm{e}-02$

3.15e-02

2.80e-02

2.45e-02

2.10e-02

$1.75 e-02$

$1.40 \mathrm{e}-02$

$7.00 \mathrm{e}-03$

$3.50 \mathrm{e}-03$
$0.00 \mathrm{e}+00$

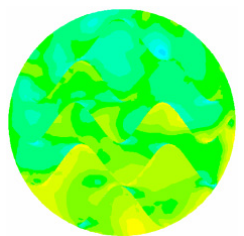

$\mathrm{L}=185 \mathrm{~cm}$

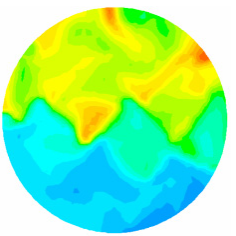

$\mathrm{L}=110 \mathrm{~cm}$

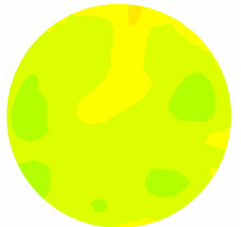

$\mathrm{L}=260 \mathrm{~cm}$

Figure 9: Volume fraction contours of caustic solution at different cross-sections through a commercial scale static mixer. 
simulated results in Figure 11. Mixture density was calculated according to the averaged caustic volume fraction along the mixer (Figure 10), which is calculated on the cross-sectional planes (Figure 9). As can be seen from Figure 11, there is a great amount of difference between measured and calculated mixture density. This is because of the location of the measuring probe, which is in the vicinity of the condensate phase, but the calculated mixture density is based on the averaged caustic volume fraction over each cross-sectional plane.

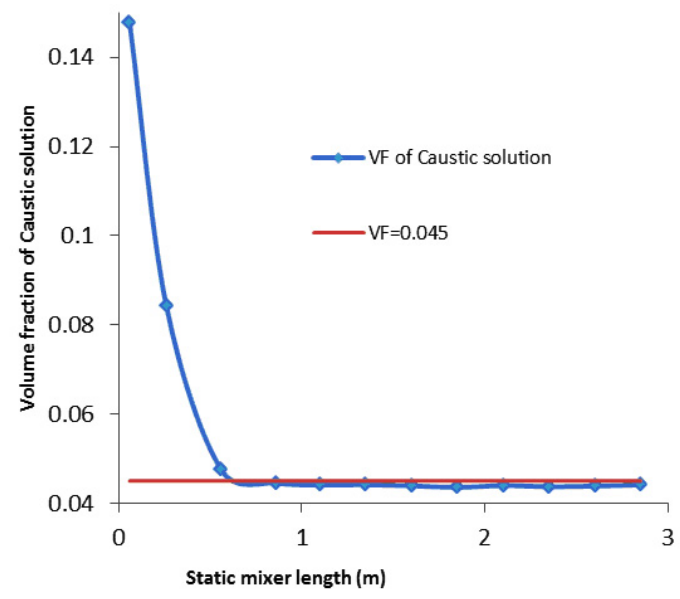

Figure 10: The area weighted average of caustic volume fraction over cross-sectional planes along the static mixer

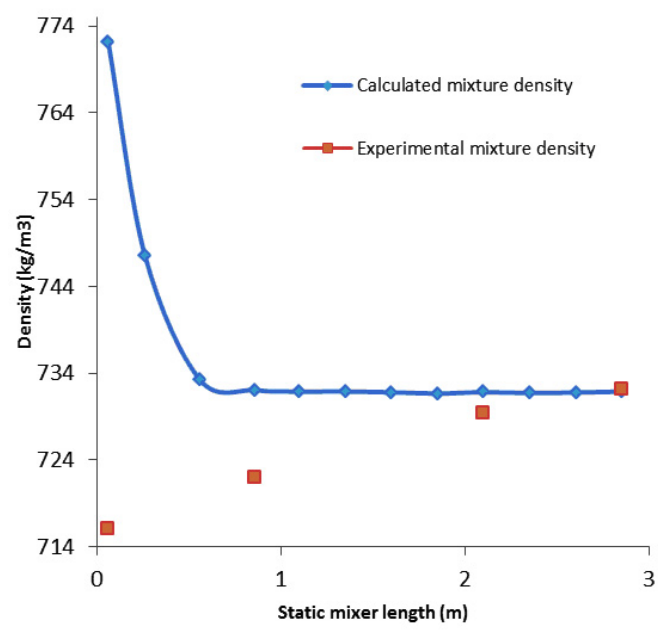

Figure 11: The comparison between predicted and experimental mixture density values at various crosssectional planes

According to the fact that the most important parameter in designing a static mixer is the mixer's pressure drop, the pressure drop of the mixture along the commercial static mixer is shown in Figure 12. According to CFD modeling, the total pressure drop of the mixture through the static mixer is $20 \mathrm{kPa}$, which is in good agreement with experimental and design data (actual pressure drop $=25 \mathrm{kPa}$, allowable pressure drop $=50 \mathrm{kPa}$ ). In Figure 12, there are three regions along the static mixer axis $(\mathrm{Z}=0.25 \mathrm{~m}, \mathrm{Z}=$ $0.75 \mathrm{~m}, Z=1.5 \mathrm{~m}$ ) where the static pressure of the mixture increases slowly. These regions are relevant to spacers where the corrugated plates do not exist.

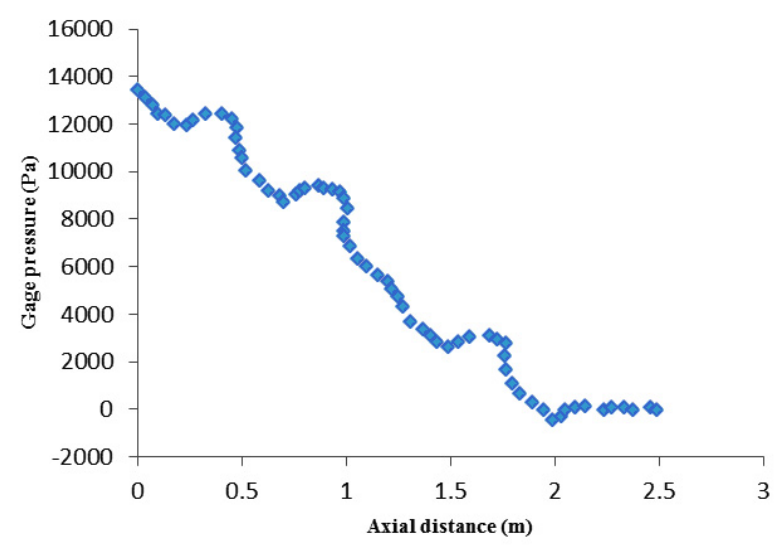

Figure 12: Mixture pressure drop versus axial position through a commercial scale static mixer.

\section{CONCLUSIONS}

In this study, a two-phase Eulerian CFD model has been developed to simulate three-dimensional liquid mixing in a specific commercial scale static mixer. There are three major parameters that are of great significance in designing a static mixer: (1) Geometrical design of the mixing elements (number of corrugated plates in a mixing element, the alignment of the corrugated plates relative to the pipe axis, the ratio of L/D for each mixing element). (2) The number of mixing elements that determine the total length of a static mixer. (3) The pressure drop of a static mixer that depends on two previous parameters. It was shown that CFD modeling can be employed as a powerful tool to evaluate the influence of design parameters on the mixing of fluids in a specified static mixer before constructing it. The patterns of flow inside a commercial static mixer, as well as the effect of spacer on pressure drop and blending of fluids, were considered. Installing a spacer after the mixing element leads to a rise in flow homogeneity and makes complete blending. As well as that, the static pressure of mixture increases 
gradually after decreasing by passing across mixing element plates and recovers somewhat the flow static pressure.

\section{REFERENCES}

Berkman, P. D. and Calabrese, R. V., Dispersion of viscous liquids by turbulent flow in a static mixer. AIChE J., 34, 602-609 (1988).

Chen, S. J. and Libby, D. R., Gas-liquid and liquidliquid dispersions in a Kenics mixer. In: 71st Annual AIChE Meeting (1978).

Cybulski, A. and Werner, K., Static mixers-criteria for applications and selection. Int. Chem. Eng., 26, 171-180 (1986).

Das, P. K., Legrand, J., Morançais, P. and Carnelle, G., Drop breakage model in static mixers at low and intermediate Reynolds number. Chem. Eng. Sci., 60, 231-238 (2005).

Fradette, L., Tanguy, P., Li, H. Z. and Choplin, L., Liquid liquid viscous dispersions with a SMX static mixer. Trans. IChemE, 85, 395-405 (2007).

Gingras, J. P., Fradette, L., Tanguy, P. and Bousquet, J., Inline bitumen emulsification using static mixers. Ind. Eng. Chem. Res., 46, 2618-2627 (2007).

Grace, C. D., Static mixing and heat transfer. Chem. Proc. Eng., 57-59 (1971).

GV Static mixer product bulletin homepage. [Online]. Available at: $<$ http://www.stamixco.com>. (Accessed: October 15, 2013).

Haas, P. A., Turbulent dispersion of aqueous drop in organic liquids. AIChE J, 33, 987-995 (1987).

Legrand, J., Morançais, P. and Carnelle, J., Liquid liquid dispersion in an SMX Sulzer static mixer Trans. IChemE, 79, 949-956 (2001).

Liu, S., Hrymak, A. N. and Wood, P. E., Drop break up in an SMX static mixer in laminar flow. Can. J. Chem. Eng., 83, 793-807 (2005).

Middleman, S., Drop size distributions produced by turbulent pipe flow of immiscible fluids through a static mixer. Ind. Eng. Chem. Process. Des. Develop, 13, 78-83 (1974).

Mutsakis, M., Streiff, F. and Schneider, G., Advances in static mixing technology. Chem. Eng. Prog., 4248 (1986).

Myers, K. J., Bakker, A. and Ryan, D., Avoid agitation by selecting static mixers. Chem. Eng. Prog., 28-38 (1997).

Rama Rao, N. V., Baird, M. H. I., Hrymak, A. N. and Wood, P. E., Dispersion of high- viscosity liquid liquid systems by flow through SMX static mixer elements. Chem. Eng. Sci., 62, 6885-6896 (2007).

Schiller, L. and Naumann, Z., A drag coefficient correlation. Ver. Deutsch. Ing., 77-318 (1935).

Shih, T. H., Liou, W. W., Shabbir, A., Yang, Z. and Zhu, J., A new k-e eddy-viscosity model for high Reynolds number turbulent flows - model development and validation. Computers Fluids, 24(3), 227238 (1995).

Streiff, F. A., Mathys, P. and Fischer, T. U., New fundamentals for liquid liquid dispersion using static mixers. Récents Prog. Génie Procédés, 11, 307-314 (1997).

Streiff, F. A., In-line dispersion and mass transfer using static mixing equipment. Sulzer Techn. Rev., 108, 113 (1977).

Thakur, R. K., Vial, K. D. P., Nauman, E. B. and Djelveh, G., Static mixers in the process industries - a review. Trans. IChemE, 81, 787-826 (2003).

Theron, F. and Le Sauze, N., Comparison between three static mixers for emulsification in turbulent flow. International Journal of Multiphase Flow, 37(5), 488-500 (2011).

Yamamoto, T., Kawasaki, H. and Kumazawa, H., Relationship between the dispersed droplet diameter and the mean power input for emulsification in three different types of motionless mixers. J. Chem. Eng. Jpn., 40, 673-678 (2007). 